Session 3542

\title{
Comparison of the Impact of Pre- and Post-Lecture Quizzes on Student Learning in an Engineering Economics Course
}

\author{
Rick T. Olson \\ University of San Diego
}

\begin{abstract}
In the past, the author has occasionally used the WebCT course delivery system to administer quizzes to encourage students to read the text before lecture. These quizzes have focused on the highlights of the material and were intended to encourage the student to come to class prepared for the lecture. During the Spring 2004 offering of Engineering Economics at the University of San Diego this practice was modified to determine whether these pre-lecture quizzes affected student learning.

One half of the class completed the quizzes before hearing the lecture on the material. The other half of the class completed the quizzes after hearing the lecture. Students also completed brief surveys assessing how well they understood each lecture immediately after the lecture. In this paper, the relationship between the timing of the quizzes and student perceptions of their understanding of the lectures is explored. The effects of quiz timing and lecture comprehension on homework and exam grades are also examined. The results of this work show that the students who read the text before the lecture tended to understand the lecture better than students who did not complete the reading assignments, and that they also performed better on exams and in the course.
\end{abstract}

\section{Introduction}

As faculty, we implore our students to come to lectures prepared to learn. Although a survey of the pedagogic literature did not reveal formal studies explicitly relating pre-reading engineering lecture material to course success, faculty assume that pre-reading is beneficial and books written by students for students even suggest that reading before a lecture will help students to learn ${ }^{1}$.

To that end, we often assign reading from course texts and expect that students will have read material before coming to class. Some students diligently perform these pre-lecture reading assignments. Other students are less thorough and skim the material or read assignments only when time permits. Many students eschew the reading assignments and use the text only as a reference while working assigned problems. 
Some of the inattention to reading assignments is understandable. Engineering students have heavy workloads and it is not always possible to read everything before class. Other times, students experience difficulties slogging through turgid material and think that they will be better able to understand the book after hearing the lecture. Whatever the reason, this inconsistent preparation by the students can complicate lecture preparation. A lecture targeted for students who have thoroughly understood the text will be quite different than a lecture for students who come to class with no exposure to the lecture topics.

When teaching in introductory operations research course to junior Industrial and Systems Engineering (ISE) a few years ago, the author used the quiz tool in $\mathrm{WebCT}^{2}$ to encourage students to read the book before lectures. Eight to ten times during the semester the WebCT quiz tool was used to prepare a short quiz over the main points of reading assignments. The quizzes were set up so that they had to be completed before the lecture; the quizzed would expire at the time of the lecture. At the end of semester a few of the students commented that they thought the quizzed helped them to prepare for the lectures by reinforcing the reading and providing some indication of the level of understanding expected before entering class.

But did the quizzes really help students learn? At one level, it didn't matter. My motivation behind the quizzes was to force the students to do the pre-class reading assignments. It was taken as a matter of faith that reading would be beneficial. But is it? And if it is beneficial, is it equally beneficial to all types of learners? Because of the small class sizes (typically 6-10 students) of ISE courses at the University of San Diego (USD) it is impractical to conduct a large-scale study to see whether forcing students to read improved learning. During the Spring 2004 semester, however, the author has the opportunity to teach the sophomore-level course Engr 50 - Engineering Economics to 16 students. Although this is still not a large number of students, it was enough to conduct a small study that used WebCT quizzes to assess the degree to which reading before a lecture helps student learning.

This paper reports the results of this study. The next section describes some the most important aspects of the course structure and how the quizzes were designed and administered. Two important questions that were pursued were: 1) Do students who read the text before class understand the lectures better than students who have not read the text?, and 2) Do students who read the text before class perform better on exams than students who do not read the text before lectures? It is important to note that there was no attempt to determine whether WebCT quizzes served to enhance learning. Rather, the quizzes served solely as a mechanism to encourage (or coerce) students to read the book before lecture.

The numerical results obtained and an analysis of the effects of pre-lecture reading and quizzes on student perceptions of their understanding of the lecture and of the relationship between reading and exam scores is then presented. Finally, some suggestions for how this work could be expanded to a larger study are given. 


\section{Course structure and study design}

Engr 50 is a semester-long, 3-unit course generally taken by sophomores at USD. The course is a "typical" course in engineering economics. Last Spring Eschenbach's Engineering Economy: Applying Theory to Practice 3 was used and the emphasis on the course was on learning the mechanics of performing economic analysis through homework problems supplemented by a few more open-ended cases. At USD, Engr 50 is a required course for all ISE majors and an approved elective for the Electrical and Mechanical engineering majors. Historically, most of the students taking the course have been ISEs and only a few EEs take the course each year. Because the ME program is new, it is difficult to assess its impact on Engr 50 enrollment. During the Spring 2004 semester there were 16 students in the course. Table 1 summarizes some of the important demographic characteristics of the class.

\begin{tabular}{|l|l|c|c|}
\hline \multicolumn{2}{|c|}{} & $\begin{array}{c}\text { Red } \\
\text { Group }\end{array}$ & $\begin{array}{c}\text { Blue } \\
\text { Group }\end{array}$ \\
\hline \multirow{2}{*}{ Sex } & Men & 5 & 5 \\
\cline { 2 - 4 } & Women & 3 & 3 \\
\hline \multirow{2}{*}{ Class } & Sophomores & 7 & 5 \\
\cline { 2 - 4 } & Juniors /Seniors & 1 & 3 \\
\hline \multirow{2}{*}{ Major } & ISE Majors & 7 & 6 \\
\cline { 2 - 4 } & EE and ME & 1 & 2 \\
\hline
\end{tabular}

Table 1 - Demographics of Engr 50 during Spring 2004 including the assignment of student to the pre-lecture quiz group (Red) and the post-lecture quiz group (Blue)

WebCT quizzes were written to correspond to 11 of the reading assignments throughout the course. These assignments corresponded to more than 11 class sessions as some "lectures" took more than one class to complete. The quizzes were quite simple and were intended to allow students to demonstrate that they were familiar with the reading and not that they had mastered the concepts. The questions were primarily multiple choice, though some matching questions were also used. The expectation was that someone who had closely read the text one time should be able to answer all the questions with minimal reference to the book. Representative quiz questions are provided in Figure 1. The scores on the quizzes were included as a part of the course homework grades.

To explore the impact of reading on student performance, the class was divided into two groups. The Red group would consist of those students required to read the text and complete a WebCT quiz before the lecture. (This lead to the mnemonic "The Red group should have read the material before class") The Blue group would complete the same WebCT quiz after the lecture has been completed. Students in the Blue group were told that they were expected to have completed the reading assignments before class, but that their quiz would take place after the lecture. A student assigned to the Blue group who normally completed the reading before class would still be able to do so. At the same time, placing a student who did not normally complete reading assignments before lecture into the Red group should not have been considered at a disadvantage because all students were assigned the reading before the lectures; the lectures were 
written assuming that the students had read the material. The quizzes taken by both groups were identical. Only the timing of the quiz changed. To ensure that students in the Red group were not disadvantaged by having to complete the quiz before hearing the lecture, students were allowed to take each quiz as many times as they desired with only the high score counting. (Interestingly, only 5 of the students earned $100 \%$ of the possible quiz points despite this scoring policy.) One disadvantage of this policy is that a student may be able to score well on quizzes without reading the book if they are patient enough to retake the quiz changing wrong answers until they find the correct responses.

Q1: Why does compound interest grow more quickly than simple interest?

a) Compound interest is based on beginning-of-period calculations.

b) More banks offer compounded interest, so they need to provide higher rates to attract customers.

>> c) Unpaid interest accrues additional interest when compounding.

Q2: When ranking projects to determine an organization's MARR, which measure is most appropriate?

a) Shortest Payback Period

b) Greatest Present Worth

c) Greatest Internal Rate of Return

d) Benefit/Cost ration or Present Worth Index

Figure 1 Representative WebCT quiz questions used in Engr 50

On the first day of class each student was asked whether they normally read the book before, or after a lecture. The plan was to use this information along with a limited understanding of some of the students' abilities to assign people to each group. As it turned out, eight people said that they normally read before lecture and eight said they wait until after. Consequently, everyone was assigned to their "natural" group. Table 1 summarizes the composition of the groups. Again, all students were assigned pre-lecture reading.

After 10 of the lectures corresponding to the reading assignments were completed, students were asked to complete the brief anonymous survey shown in Figure 2. Each student used their own perceptions of words such as "most" or "fully." This survey was the sole measure of how well the students understood a lecture. There were no end-of-lecture exercises that tested actual knowledge. The surveys were used to relate student perceptions of their understanding of lectures to their assigned groups and to determine whether the students in each quiz group had done the reading before the lectures.

This study was clearly explained to the students and they were told that their participation in the post-lecture comprehension survey was voluntary and that they could elect to have their scored excised from any extracurricular analysis. They were also told that the aggregate results of the Red and Blue groups on the mid-term exams would be shared and that students could switch groups at any time if they thought it would help their performance in the course. All students signed consent forms. No students changed groups during the semester. 


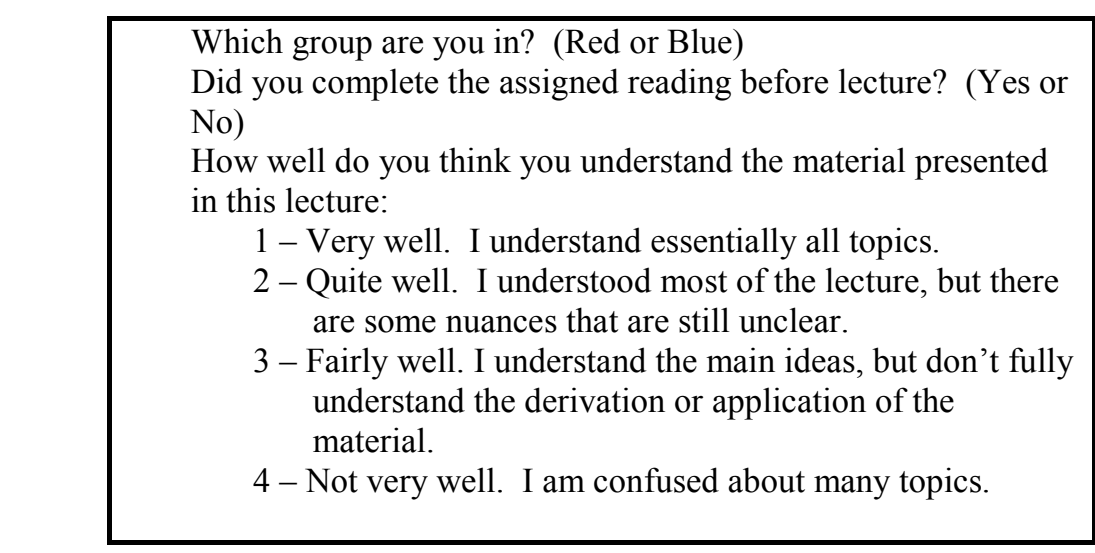

Figure 2 Survey completed by each student after 10 of the lectures during the Spring 2004 offering of Engr 50.

\section{Results and analysis}

As mentioned above, there were 11 quizzes administered in conjunction with reading assignments throughout the semester. After 10 of the corresponding lectures (which sometimes spanned two class sessions), the survey in Figure 2 was distributed to gather information about student behaviors and learning. This section presents the results of a series of questions related to the relationship between the timing of reading (and quizzes) and class performance. Some of the answers remain elusive because of shortcomings in the administration of the course that were not apparent the course was offered. Minitab ${ }^{4}$ was used to perform all statistical calculations and tests.

Q1: Was the Red group more likely than the Blue group to read the text before lecture?

$A$ : Resoundingly, yes. $68.9 \%$ of the post-lecture survey forms returned by Red students indicated that they had read the chapter. $7.8 \%$ of the forms from Blue students said they read the material. In fact, only 5 of the 64 forms completed by Blue students indicated that they had read the material before lecture. The null hypothesis that the proportion of students who read the text is the same in both groups was rejected by applying Fischer's exact test to the contingency table formed by the data. The null hypothesis was rejected in favor of the alternate that the groups had different reading habits with a $p$-value of .000000 . Fischer's test was used rather than a Chi-squared test because of low cell counts in the contingency table.

Q2: Was the Red group more likely to read the text if there was a pre-lecture Quiz than if there wasn't a quiz?

$A$ : This is an open question because no post-lecture surveys were collected for lectures without a corresponding quiz. This was an oversight in the design of the study that should be explored further. In light of the correlation between pre-lecture reading and exam performance (see Q6) it may be appropriate to offer more pre-lecture quizzes if they encourage reading. 
Q3: Did the Red group understand the lectures better than the blue group?

$A$ : Yes. Because reading the book in advance of the lecture is expected to improve the comprehension of the lecture, this was treated as a one-tailed hypothesis test with $\mathrm{H} 1$ : $\mu_{\mathrm{R}}<\mu_{\mathrm{B}}$. (Recall that low numbers reflected greater understanding of the reading) Figure 3 illustrates the student responses. The mean response of the Red group was 2.07. The Blue response was 2.74. A $t$-test for the difference of means revealed a $t$-value of 4.38 and a $p$ value of .000. Consequently, $\mathrm{H} 1$ is accepted.

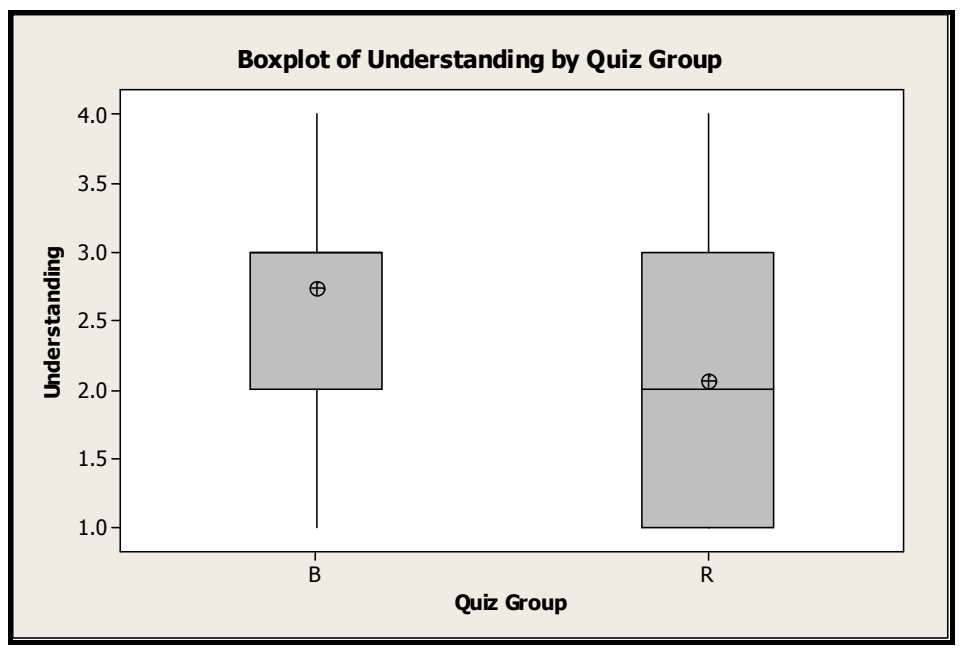

Figure 3 Comparison of lecture comprehension as reported by students in the Blue and Red Quiz Groups.

Q4: Did people who read the text understand the lectures better than people that did not (regardless of which group they were in)?

$A$ : Yes. This is a similar result to $Q 3$ but acknowledges those instances when students in the Blue group read the text before class. Figure 4 illustrates the student responses. This was treated as a one-tailed hypothesis test with $\mathrm{H} 1: \mu_{\text {Read }}<\mu_{\text {NotRead. }}$. The mean response all people who read before a lecture was 1.89. The response of people that did not read before lecture was 2.71. A $t$-test revealed a $t$-value of 5.43 and a $p$-value of .000 causing $\mathrm{H} 1$ to be accepted.

Q5: Were mean quiz scores higher for students in the Blue group?

$A$ : No. In fact, the average quiz score was lower for the Blue group. The average person in the Red group achieved $90.1 \%$ of all possible quiz points. The average person in the Blue group scored $79.6 \%$. After removing one student in the Blue group who only took one quiz the average is only raised to $88.3 \%$. A $t$-test was performed to assess $\mathrm{H} 0: \mu_{\text {Red }}=\mu_{\text {Blue }}$ vs. H1: $\mu_{\text {Red }} \neq \mu_{\text {Blue. }}$ The $p$-value was .687 indicating that there was no statistically significant difference in the quiz results. Concerns that the Red group might be disadvantaged because they had to complete the quizzes before the lecture were not supported. 


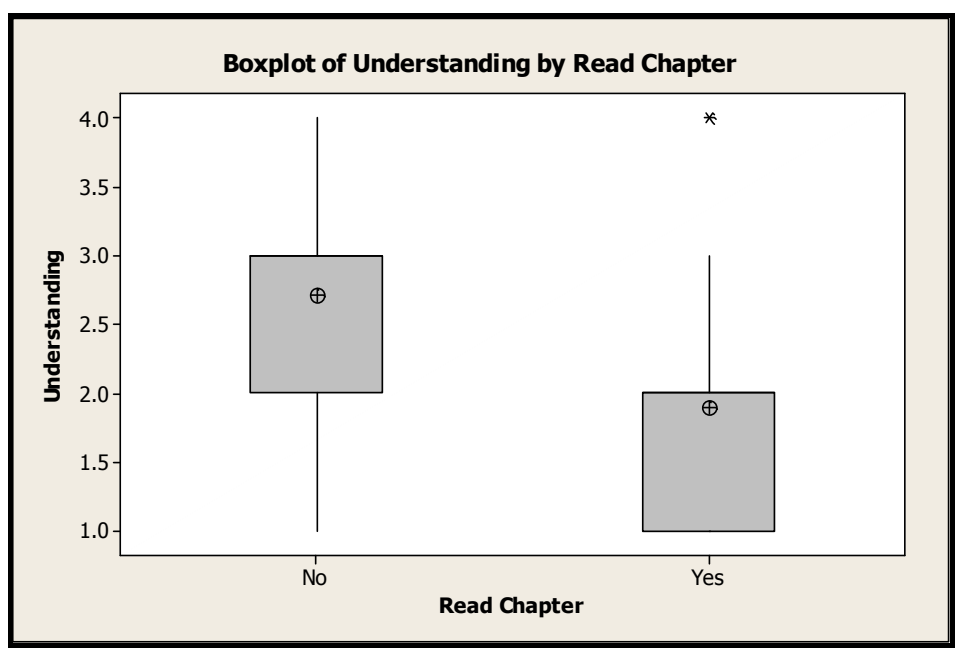

Figure 4 Comparison of lecture comprehension as reported by students in the Blue and Red Quiz Groups.

Q6: Did the Red group perform better on exams and the entire course?

A: $\quad$ Figure 5 shows how students performed on the exams. Figure 6 shows overall course performance. Table 2 summarizes the statistics for this question. All comparisons were $t$ tests for differences in the mean score with H0: $\mu_{\text {Red }}=\mu_{\text {Blue }}$ vs. H1: $\mu_{\text {Red }}>\mu_{\text {Blue. }}$ Because we were seeking evidence that pre-reading improves student learning, the alternate hypothesis in this case was that students in the Red group would score higher than students in the Blue group. The differences in group performance are less pronounced here than might be expected. In fact, only the results for Exam 1 and Overall Course \% are significant at $\alpha=.05$.

Besides the results shown above, 6 of the top 7 students in the course were in the Red group, while 5 of the bottom 6 scores were in the blue group. Although the WebCT quizzes may not directly relate to course performance, it does appear that the better students do make a habit of reading the text before lectures. Recall that the Red and Blue teams were formed based on existing student behaviors.

\begin{tabular}{|l|c|c|c|c|}
\hline & $\begin{array}{c}\text { Mean Red } \\
\text { Group Score }\end{array}$ & $\begin{array}{c}\text { Mean Blue } \\
\text { Group Score }\end{array}$ & $t$-value & $p$-value \\
\hline Exam 1\% & 72.4 & 61.5 & 1.96 & 0.036 \\
\hline Exam 2\% & 82.0 & 75.9 & 1.21 & .125 \\
\hline Exam 3\% & 78.75 & 76.5 & .59 & .284 \\
\hline Final \% & 76.9 & 70.1 & 1.25 & .116 \\
\hline Course \% & 81.57 & 74.35 & 1.81 & .047 \\
\hline
\end{tabular}

Table 2 Statistical comparison of exam and course performance by students in the Red and Blue Groups 


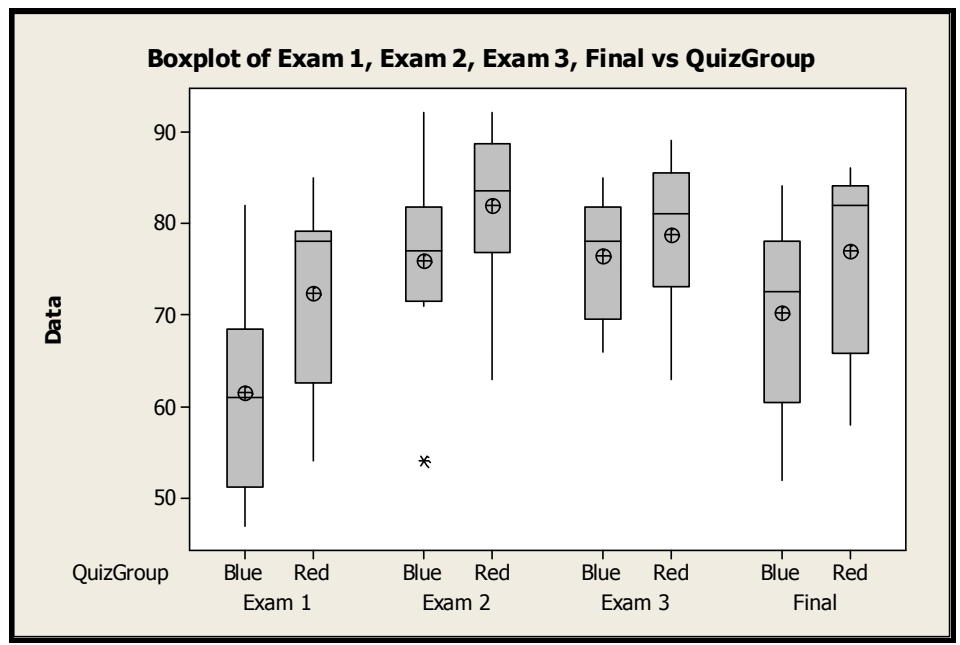

Figure 5 Comparison of exam performance by students in the Blue and Red Quiz Groups.

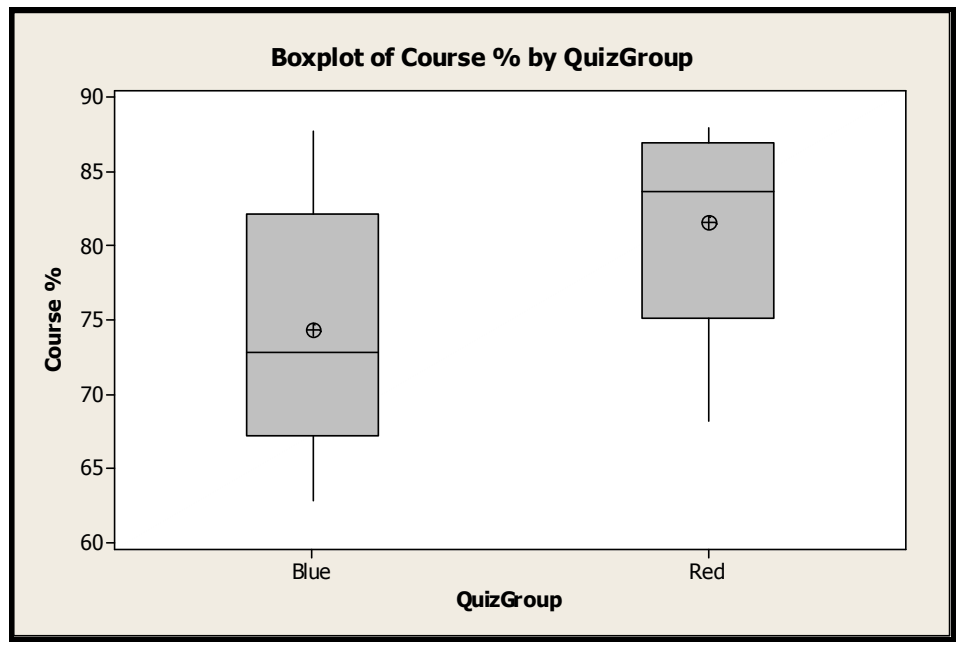

Figure 6 Comparison of course performance by students in the Blue and Red Quiz Groups.

\section{Suggestions for future work}

This study was intended as a pilot study to determine whether a larger investigation is warranted. The results indicate that there are connections between before lecture reading, student understanding of lectures, and course performance. It would be beneficial, however, to perform a similar study with larger sections in other course to better understand the impact of reading, and of pre-lecture quizzes to reinforce the reading. In the process of extending this work two simple modifications to the process should be explored:

1) Not all reading assignments should have quizzes associated with them and the postlecture survey should be administered after the corresponding lectures. This will help to 
understand whether students are equally likely to read the text whether or not there is a pre-lecture quiz.

2) GPAs should be considered when assigning people to teams and some people who are predisposed to pre-reading should be assigned to the Blue group and post-readers assigned to the Red group. These measures would make it possible to better determine whether quizzes can affect student behavior and whether the timing of the quizzes affects their impact on reinforcing student learning

\section{References}

[1] Donaldson, K, The Engineering Student Survival Guide, WCB/McGraw-Hill, 2001.

[2] http://www.WebCT.com

[3] Eschenbach, T. G., Engineering Economy: Applying Theory to Practice, Oxford University Press, 2004.

[4] Minitab User's Guide 2: Data Analysis and Quality Tools, Minitab, Inc, 2003.

\section{Biographical Information}

RICK T. OLSON is an Associate Professor of Industrial and Systems Engineering at the University of San Diego.

His teaching and research emphasis is in applied operations research. He received a B.S. in Mechanical Engineering, an M.S. in Industrial Engineering and a Ph.D. in Mechanical Engineering with an emphasis in operations research from the University of Illinois at Urbana-Champaign. 